\title{
ANALYSIS OF MPPT TECHNIQUES APPLIED TO THE DCM MULTIPHASE BOOST CONVERTER FOR THE MITIGATION OF PARTIAL SHADING IN PV ARRAYS
}

\author{
Pedro de Assis Sobreira Jr. ${ }^{1}$, Fernando Lessa Tofoli ${ }^{2}$, Henrique Antônio Carvalho Braga ${ }^{1}$, \\ Pedro Gomes Barbosa ${ }^{1}$, André Augusto Ferreira ${ }^{1}$ \\ (1) UFJF - Univ. Federal de Juiz de Fora - Juiz de Fora-MG, Brazil. E-mail: pedro.sobreira@engenharia.ufjf.br, \\ henrique.braga@ufjf.edu.br, pedro.gomes@ufjf.edu.br, andre.ferreira@engenharia.ufjf.br \\ (2) UFSJ - Univ. Federal de São João del-Rei - São João del-Rei-MG, Brazil. E-mail: fernandolessa@ufsj.edu.br
}

\begin{abstract}
This work presents the study and implementation of a multi-input dc-dc interleaved boost converter used in solar photovoltaic systems. Initially, a comparative analysis between two popular techniques used to track the maximum power point is performed to demonstrate whether controlling the PV array voltage or current has significant impact on the solar energy conversion into electricity. Due to their popularity, perturb and observe and incremental conductance are chosen and evaluated through simulation tests. Considering that the results obtained with both techniques controlling either the voltage or the current of the modules are similar, incremental conductance is implemented in and dc-dc interleaved boost converter operating in discontinuous current mode. Thus, it is possible to mitigate the partial shading effects on photovoltaic arrays, also reducing size of passive elements and providing fast transient response. Experimental results on a PV system using a digital signal processor are presented to validate the proposed approach.
\end{abstract}

Keywords - Interleaved converters, MPPT, Photovoltaic power systems, Solar energy.

\section{INTRODUCTION}

In the next few years, the world is supposed to face several problems related to the exhaustion of some energy sources, mainly those regarding fossil fuels [1]. It is also well known that some aspects concerning the increase of oil price due to economical and political matters have been the cause of economic crisis in the last decades [1]. The search for renewable energy sources then becomes more and more intense as a prominent alternative for the mitigation of the world energy crisis.

Among the clean and green power sources, the photovoltaic (PV) solar energy comes up as an interesting alternative to supplement the generation of electricity [2]. The significant cost reduction of PV modules in the last few years have made the use of solar energy particularly attractive, mainly in small single-phase residential systems connected to the utility grid and standalone applications [3].

As the PV cells generate dc voltage, a power conditioning system is also required, in order to suit the frequency and

Manuscript received on 19/06/2012. Revised on 17/04/2013 and on $16 / 10 / 2013$. Accepted for publication in $16 / 10 / 2013$, by recommendation of the Editor João Onofre Pereira Pinto. voltage level to the utility grid and allow the parallel connection. In addition, a PV system must present some features related to the safety, efficiency, and power quality. A required feature of a PV system is the ability to track the maximum power point (MPP) of the PV array [4]. Besides, MPP tracking (MPPT) is desirable in both grid-connected and stand-alone photovoltaic systems because both the solar irradiance and operating temperature of the PV module change throughout the day, as well as along seasons and geographical conditions, also leading to the modification of $I \times V$ (current versus voltage) and $P \times V$ (power versus voltage) curves that determine its behavior. The application of MPPT is also justified by the relatively high cost of the kilowatthour generated by PV systems if another energy sources are considered.

A PV system is typically composed by a PV array, an intermediate dc-dc stage, and a dc-ac converter that allows obtaining ac voltages in either grid-connected or stand-alone applications. The dc-dc converter plays an important role not only in the voltage step-up of the PV modules, but also in the achievement of the MPP. Literature presents numerous examples of power converter topologies adequate for this purpose e.g. the dc-dc interleaved boost converter [5]. Prominent advantages are increase of the frequency for which the magnetic elements are designed, also partially canceling the input and output ripples, with consequent reduction of size of the energy storage inductors and differential-mode electromagnetic interference (EMI) filters. This converter is also adequate for high-current applications as the number of involved phases can be increased according to the power processed by the PV system.

Within this context, the scope of this paper is divided in two distinct parts. Firstly, it aims to investigate which is the preferable variable to be controlled in the MPPT algorithm. That is, voltage MPPT (VMPPT) and current MPPT (CMPPT) control will be analyzed, simulating the impact of the variation of irradiance and temperature on the performance of two well-known MPPT methods i.e. pertub and observe (P\&O) and incremental conductance (IC). Secondly, a multi-input converter based on the interleaved boost topology operating in discontinuous conduction mode (DCM) is studied, which has not been presented in literature before in such type of application. A digital signal processor (DSP)-based approach is used to track the MPP in each phase, as the effect of partial shading on a given PV module or cell is not supposed to affect the power extraction from the remaining strings. 


\section{REVIEW OF MPPT ALGORITHMS}

Typical algorithms used to determine the MPP are $\mathrm{P} \& \mathrm{O}$, IC, parasitic capacitance (PC), and constant voltage (CV), even though many others exist in literature [6]. The comparison of performance regarding numerous MPPT techniques is not new and has also been the scope of some papers, what is discussed as follows.

The work developed in [7] describes an experimental comparison of techniques regarding the efficiency of the aforementioned algorithms. It is shown that $\mathrm{P} \& \mathrm{O}$ algorithm is the most commonly used in commercial converters. IC has a performance level close to $\mathrm{P} \& \mathrm{O}$, but in general the higher implementation cost compared to $\mathrm{P} \& \mathrm{O}$ would not be justified by an improvement in performance. The PC method leaves some doubt about an implementation in commercial PV because of the use of large input capacitors. At last, the $\mathrm{CV}$ method has shown the worst MPPT efficiency, despite being the simplest and less expensive alternative.

The study carried out in [8] focuses on various MPPT techniques from the analysis of over 90 compiled papers. Methods such as $\mathrm{P} \& \mathrm{O}$ and hill climbing (HC) are found to be of simple implementation in either analog or digital forms. On the other hand, IC is slightly more complex and requires digital circuitry. However, the choice of a given method depends on engineers' and designers' knowledge and familiarity with analog and digital circuitry [8].

The comparison of several MPPT techniques applicable to grid-connected inverter configurations operating in DCM has been discussed in [9], where both dynamic and steady-state performances are evaluated. The work mentions that the choice of a given MPPT scheme depends on the application type. Besides, HC and IC are able to track the MPP accurately for all environmental conditions, since appropriate perturbation steps on voltage or current reference are used for tracking. However, they require comparatively larger time to track MPP if compared to other methods such as CV [9].

Another comparison involving ten popular algorithms including $\mathrm{P} \& \mathrm{O}$ and IC is presented in [10], while the conclusions are similar to those obtained in [7]-[9]. If other methods such as PC are considered, $\mathrm{P} \& \mathrm{O}$ and IC aggregate prominent advantages such as relatively simple implementation and low cost associated to fast convergence speed if adequate steps are used, and satisfactory accuracy.

By considering the aforementioned methods, MPPT can be achieved by monitoring and controlling either the voltage or current of the PV array. However, it seems that literature does not come to a common sense conclusion about which is the best choice regarding the achieved efficiency. This fact is evidenced in the aforementioned works [7]-[10].

The output power of PV arrays decreases significantly when one or more of the panels that exist in the array are subjected to shading. Partial shading can be caused by the shadows of buildings, trees, and poles. In large PV systems, moving clouds may also lead to partial shading. Partial shading complicates the PV characteristics with multiple peaks, apart from reducing the energy extraction from PV systems. The occurrence of such multiple peaks can mislead some MPPT algorithms to get trapped at local peaks [11].
The partially shaded condition is not considered in [7][10], while irradiation is assumed to be uniformly spread over the PV array. In cases in which one or more of the PV modules comprising the PV array are shaded (e.g., due to dust, shading from surrounding buildings, trees or poles, etc.), the $P \times V$ characteristic of the PV array exhibits multiple local maxima and only one of them corresponds to the global MPP [12]. Under partial-shading conditions, the conventional MPPT techniques fail to guarantee successful tracking of the global MPP [12] [13].

The connection of PV cells and modules in parallel in order to avoid the effect of partial shading is an interesting solution, even though it is restricted to low and medium power applications due to the number of converters and components that may be necessary to increase power [12] [14]. Distributed MPPT (DMPPT) is used in [15], where a $\mathrm{dc} / \mathrm{dc}$ power converter with MPPT controller is incorporated to each PV module of the PV string, thus increasing the total available MPP power of the array.

However, the approach in [15] is based on the buck converter and is only adequate for standalone applications and battery charging. If a grid-connected system is considered instead, many series-connected PV panels are necessary to supply the dc link of the dc-ac stage, and boostbased topologies are able to reduce the number of required panels significantly [16].

As it was mentioned before, several MPPT algorithms exist in literature [7]-[10], while some of them are popular for their simplicity and robustness e.g. P\&O and IC. A brief review of concepts involving such methods is presented as follows, since they will be analyzed in detail in this work.

\section{A. $P \& O$}

$\mathrm{P} \& \mathrm{O}$ is one the simplest MPPT methods [17]-[20] with excellent performance and can be easily implemented in low cost systems [20]. Some more sophisticated methods are based on the same principle employed in $\mathrm{P} \& \mathrm{O}$ method e.g. $\mathrm{HC}$ and modified $\mathrm{HC}$ [8].

Figure 1 shows the flowchart representation of $\mathrm{P} \& \mathrm{O}$ technique, where $V(k)$ and $I(k)$ are the present voltage and current of the PV array, and $V(k-1)$ and $I(k-1)$ are their previous values, respectively. The principle lies in disturbing the voltage or the current of the PV module and observing its effect on the resulting power. The algorithm compares the power of the previous step with that for next step so that it can increase or decrease the voltage or current. This method changes the reference value, which can be a constant current or voltage. The operating point is then periodically moved towards the MPP by either increasing or decreasing the array voltage or current.

$\mathrm{P} \& \mathrm{O}$ method works well when the irradiance does not vary quickly with time. Thus, the power oscillates around the MPP in steady state operation and it is not good when there are fast variations of temperature and solar irradiance.

\section{B. IC}

IC has been proposed as a solution to overcome some limitations of the $\mathrm{P} \& \mathrm{O}$ method, such as convergence speed and steady-state error [21]. Often cited as the best technique based on the principle of disturbance and observation, it 
aggregates some prominent advantages such as easy and fast response to rapidly changing solar irradiances. In the IC method, the derivative (conductance) of the $P \times V$ curve is used by the algorithm, which is represented in Figure 2. The error is reduced because the operation point is less disturbed than in the P\&O method. It is based on the fact that the derivative of power with respect to voltage $V$ (IC) or current $I$ (incremental impedance - II) at the MPP is null. Under such condition, the following expressions result:

$$
\begin{aligned}
& \frac{d P}{d V}=\frac{d(V \cdot I)}{d V}=I \cdot \frac{d V}{d V}+V \cdot \frac{d I}{d V}=I+V \cdot \frac{d I}{d V} \\
& \frac{d P}{d I}=\frac{d(V \cdot I)}{d I}=I \cdot \frac{d V}{d I}+V \cdot \frac{d I}{d I}=V+I \cdot \frac{d V}{d I}
\end{aligned}
$$

From the calculation of $\Delta V$ and $\Delta I$, and by using the $\mathrm{c}$ values of $V$ and $I$, expressions (1) and (2) can be employed in the algorithm decisions, thus comparing the instantaneous conductance $I / V$ and the incremental conductance i.e. [8]:

$-\Delta I / \Delta V=-I / V$ : the operating point lies exactly in the MPP;

$-\Delta I / \Delta V>-I / V$ : the operating point lies to the left of the MPP;

- $\Delta I / \Delta V<-I / V$ : the operating point lies to the right of the MPP.

Based on the results of the comparisons above, the algorithm takes the decision to increase or decrease the voltage across the PV array.

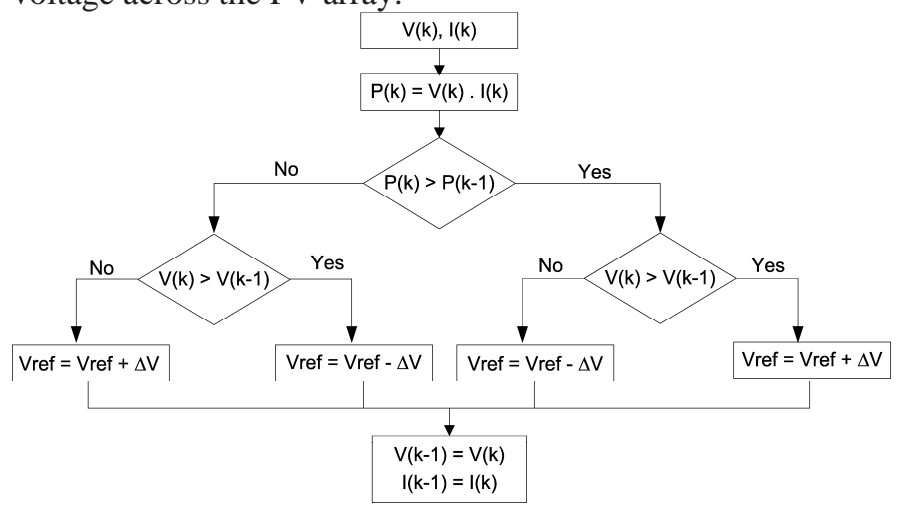

Fig. 1. $\mathrm{P} \& \mathrm{O}$ algorithm.

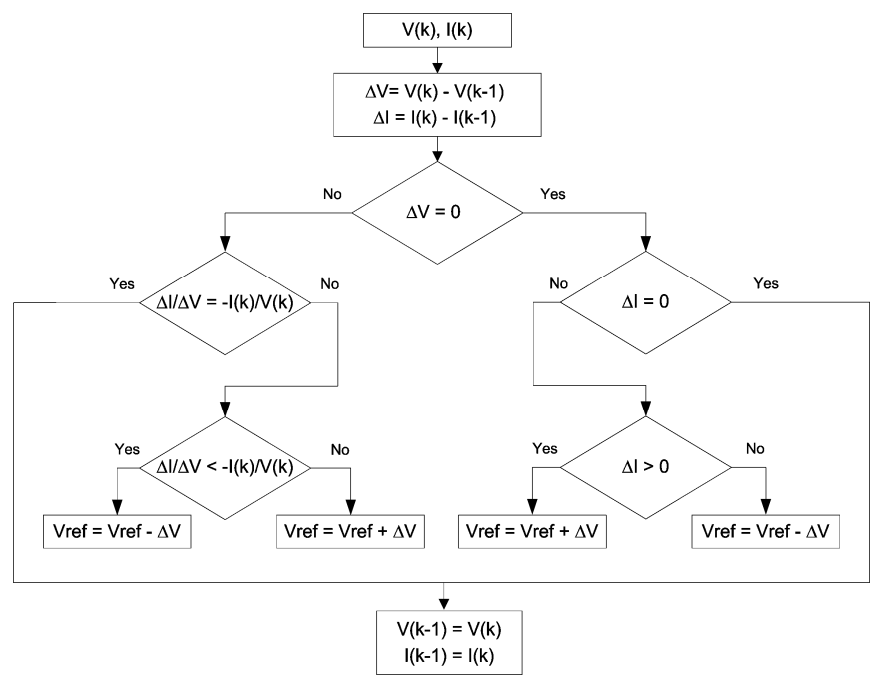

C. MPPT Control Variables and Comparison Between $P \& O$ and IC Techniques Using VMPPT and CMPPT

As it was mentioned before, a dc-dc converter corresponds to the interface between the PV array and the load, which may be a battery bank or the first stage of a grid-connected system, as shown in Figure 3.

For a given operating condition, the MPPT algorithm can provide a current reference (CMPPT) or a voltage reference (VMPPT) to the converter controller operating in closed loop. The reference provided by the MPPT block represents the position of the MPP. Another possible configuration is the direct duty cycle control, where the MPPT acts directly on the turn on and turn off of the controlled switch [22]. However, the latter technique subjects the converter to excessive stress and increased losses [23].

The choice between the voltage and current to track the MPP is thoroughly discussed in literature [24]-[28]. According to [24], due to the fact that the PV array voltage remains relatively constant over a wide range of the solar radiation, the choice of voltage control is better recommended. The authors in [25] say that the current through the PV array varies strongly with the radiation. And yet, the transient responses of the MPPT algorithm may cause the saturation of the PV array at short circuit condition, resulting in a sudden drop in voltage and extracted power [25] [26]. However, the work developed in [27] proposes the control of the PV array current and concludes that it is more advantageous compared to the voltage control using the IC method. The aforementioned works have in common the analysis of each method through assumptions made based only on the characteristic curves of PV panels.

The PV system employed in this study consists of an array formed by two series-connected BP SX 120 modules whose characteristics are given in Table I [29], a conventional dc-dc boost converter, and a constant-voltage DC bus at the converter output. Some simulation results are presented and discussed as follows, aiming to determine which method is more efficient by sensing either the current or the voltage of the PV array.

Let us consider a hypothetical case where the solar irradiation and temperature vary in the step form according to the pattern in Figure 4 as follows:

- $A: 800 \mathrm{~W} / \mathrm{m}^{2}, 32{ }^{\circ} \mathrm{C}$;

- B: $1000 \mathrm{~W} / \mathrm{m}^{2}, 32{ }^{\circ} \mathrm{C}$;

- $C: 1000 \mathrm{~W} / \mathrm{m}^{2} ; 20^{\circ} \mathrm{C}$

- D: $1000 \mathrm{~W} / \mathrm{m}^{2} ; 32^{\circ} \mathrm{C}$;

- $E: 800 \mathrm{~W} / \mathrm{m}^{2}, 32^{\circ} \mathrm{C}$.

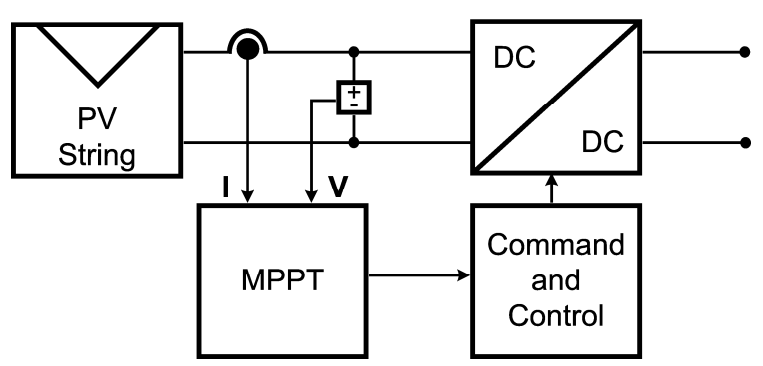

Fig. 3. Generic PV system.

Fig. 2. IC algorithm. 
Figure 4 shows that the methods present nearly the same results, being able to track the MPP satisfactorily with negligible error. However, it can be seen that the response of the controller is slower when the current through the array is used in the MPPT, as in Figure 4 (c) and (d).

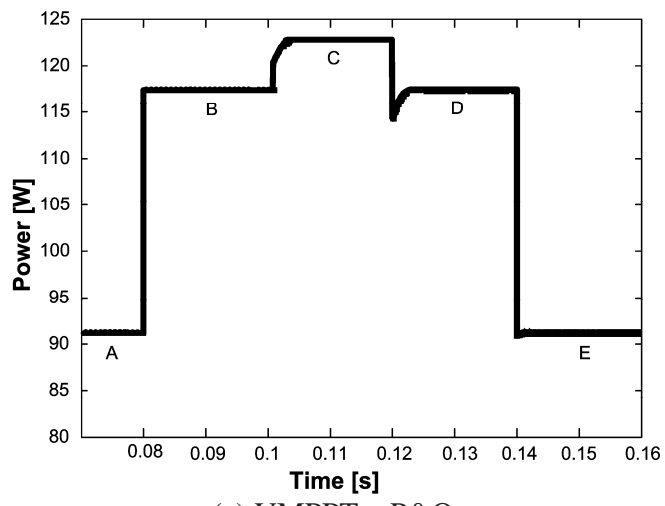

(a) VMPPT $-\mathrm{P} \& \mathrm{O}$

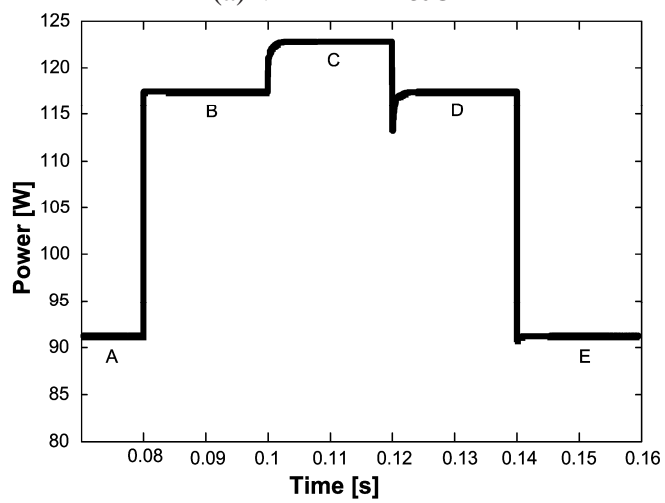

(b) VMPPT - IC

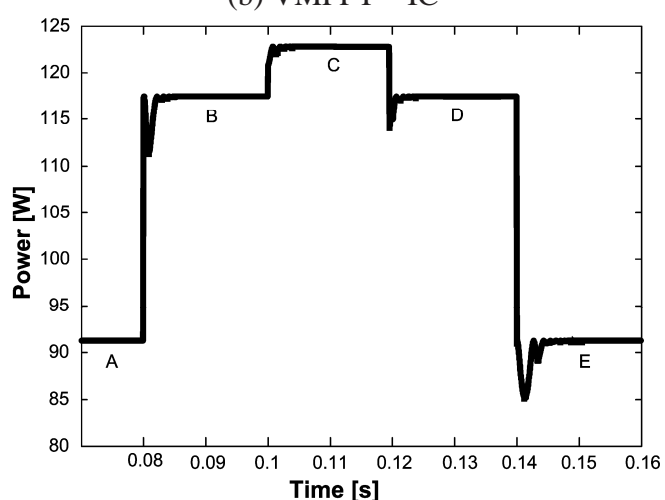

(c) $\mathrm{CMPPT}-\mathrm{P} \& \mathrm{O}$

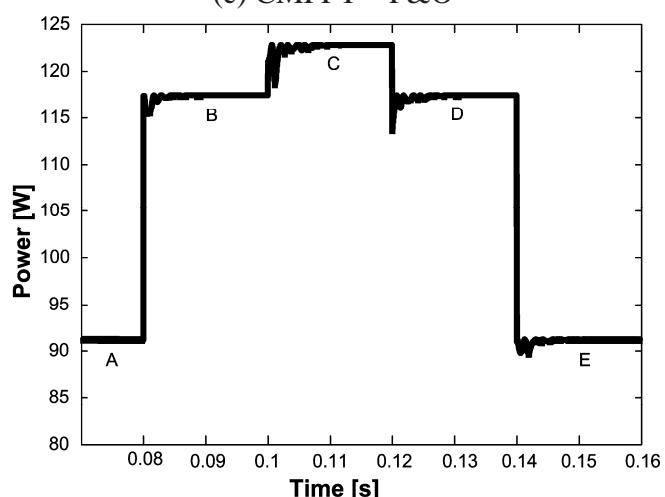

(d) CMPPT - IC

Fig. 4. Power extracted from the PV array considering that the solar radiation and/or the temperature vary quickly.
It is also important to analyze the behavior of the aforementioned methods when the solar radiation and air temperature vary over one day. For this purpose, data measured in the city of Botucatu, Brazil and shown in Figure 5 and Figure 6 will be used in the simulations. It is worth to mention that they represent real profile curves characteristic of typical weather in Brazil [30], although data acquisition was not performed by the authors.

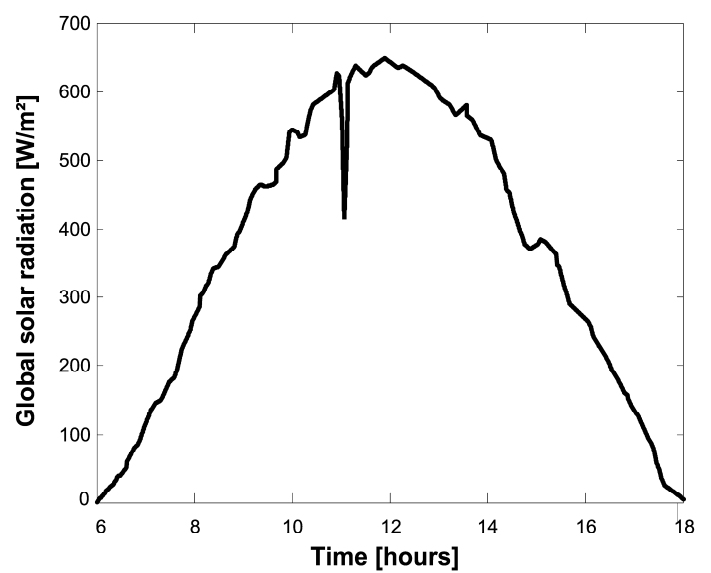

Fig. 5. Global solar irradiation in Botucatu, Brazil measured on 06/23/1998 [30].

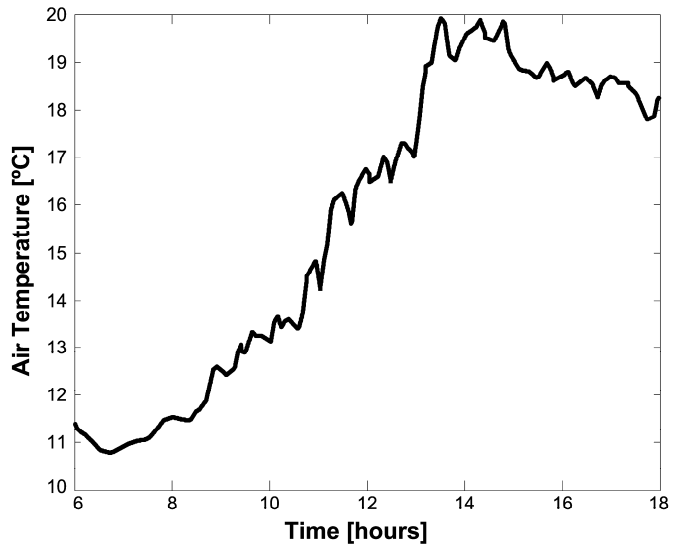

Fig. 6. Air temperature measured on 06/23/1998 with a meteorological station in Botucatu, Brazil [30].

TABLE I

Typical Electric Characteristics of PV Module BP SX 120 [29].

\begin{tabular}{lc}
\multicolumn{1}{c}{ Parameter } & Value \\
\hline Maximum power $\left(P_{\max }\right)$ & $120 \mathrm{~W}$ \\
Voltage at $P_{\max }\left(V_{m p}\right)$ & $33.7 \mathrm{~V}$ \\
Current at $P_{\max }\left(I_{m p}\right)$ & $3.56 \mathrm{~A}$ \\
Warranted maximum power $P_{\max }$ & $110 \mathrm{~W}$ \\
Short-circuit current $\left(I_{s c}\right)$ & $3.87 \mathrm{~A}$ \\
Open-circuit voltage $\left(V_{o c}\right)$ & $42.1 \mathrm{~V}$ \\
Temperature coefficient of $I_{s c}$ & $(0.065 \pm 0.015) \% /{ }^{\circ} \mathrm{C}$ \\
Temperature coefficient of $V_{o c}$ & $-(80 \pm 10) \mathrm{mV} /{ }^{\circ} \mathrm{C}$ \\
Approximate effect of temperature on power & $-(0.5 \pm 0.05) \% /{ }^{\circ} \mathrm{C}$ \\
NOCT & $47 \pm 2{ }^{\circ} \mathrm{C}$ \\
Maximum system voltage & $600 \mathrm{~V}$ \\
\hline
\end{tabular}


Figure 7 shows the behavior of the output power using $\mathrm{P} \& \mathrm{O}$ and IC when both CMPPT and VMPPT are implemented. The full range of the PV array was used to determine the perturbation steps. The chosen values for the

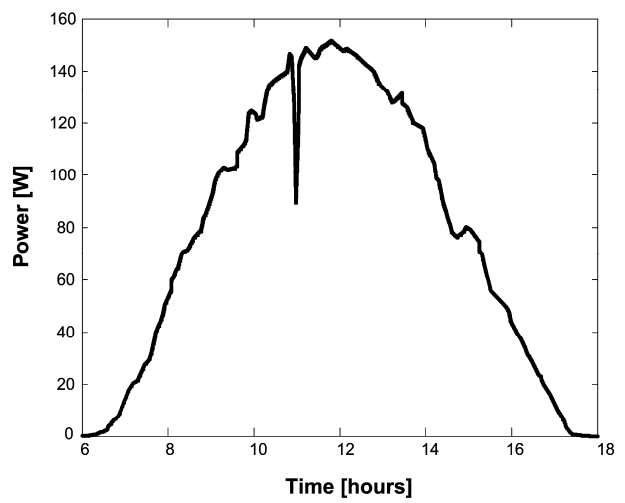

(a) VMPPT - P\&O

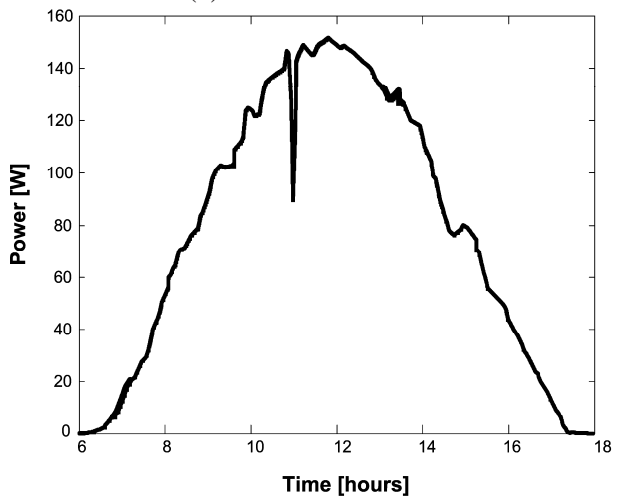

(b) VMPPT - IC

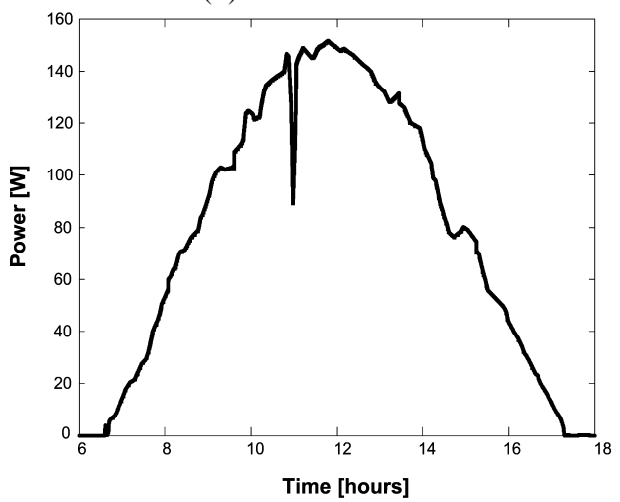

(c) $\mathrm{CMPPT}-\mathrm{P} \& \mathrm{O}$

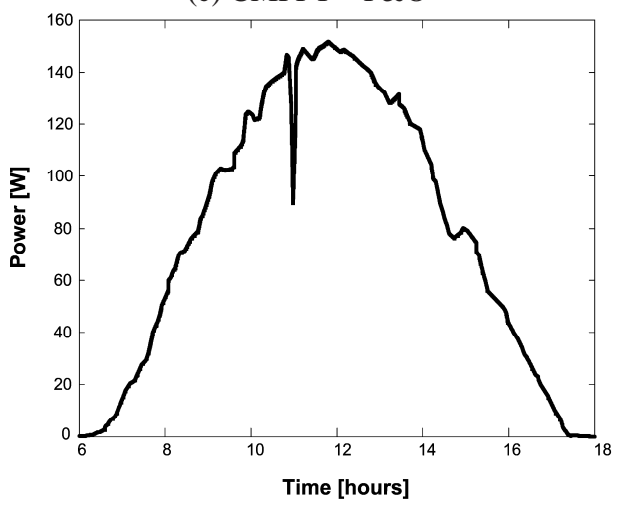

(d) CMPPT - IC

Fig. 7. Output power profile of the $\mathrm{PV}$ array using $\mathrm{P} \& \mathrm{O}$ and IC. perturbation steps correspond to the values of the open circuit voltage and short-circuit current of the array divided by 1000 . Since both solar irradiation and temperature in practice usually vary smoothly during the day, oscillation and slow response of the controllers are not verified. Once again, the obtained results are nearly the same for all methods.

However, in order to establish a fair comparison, the energy extracted from the PV array was measured considering the profiles given in Figure 5 and Figure 6. Table II shows that the performances of the methods are similar, while the difference in the extracted energy between the most efficient one and the least efficient method one is $0.022 \%$.

This result is particularly important and interesting, because VMPPT or CMPPT techniques produce nearly the same results, but the control of current or voltage by the power converter is concerned with the system stability.

Additionally, it is important to give special attention to the choice of an adequate disturbing step for the MPPT algorithm. A wrong choice can lead to power losses due to the saturation of the panel current or voltage, which may assume short-circuit current or open circuit voltage condition, respectively, as shown in Figure 8. For this simulation, IC with current control is employed. At the points highlighted in Figure 8, the algorithm increments the reference current and the output current almost assumes the short-circuit condition due to the extremely large perturbation step. Therefore there is a decrease of the voltage across the PV array and power loss occurs. This situation can be avoided by choosing the appropriate perturbation step i.e. the disturbing step should be smaller in this case.

TABLE II

Energy extracted from the PV array using distinct MPPT methods.

\begin{tabular}{lc}
\hline \multicolumn{1}{c}{ Method } & Extracted Energy \\
\hline VMPPT - P\&O & $1141.27 \mathrm{Wh}$ \\
CMPPT - P\&O & $1141.14 \mathrm{Wh}$ \\
VMPPT - IC & $1141.27 \mathrm{Wh}$ \\
CMPPT - IC & $1141.02 \mathrm{Wh}$ \\
\hline
\end{tabular}
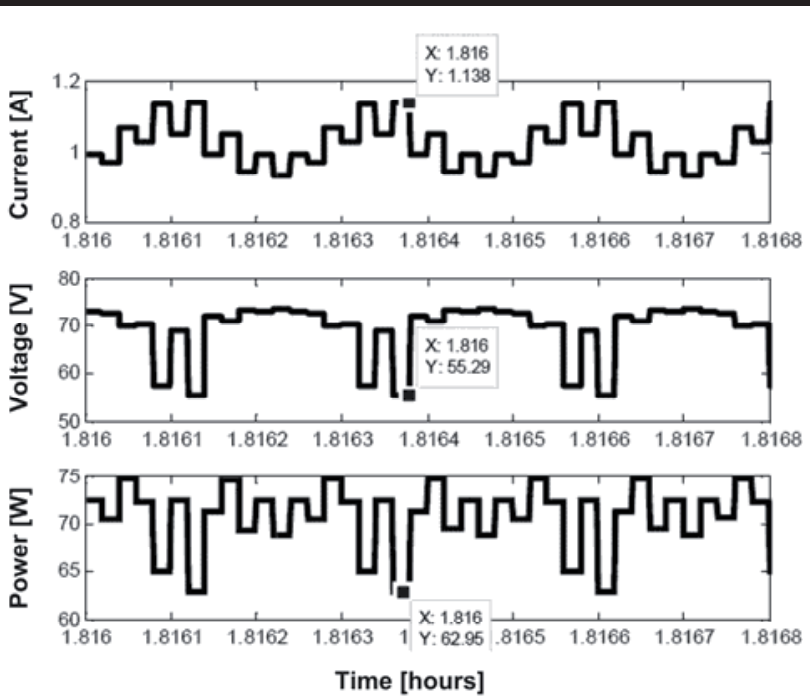

Fig. 8. Behavior of IC MPPT technique when an inadequate disturbing step is used. 


\section{INTERLEAVED BOOST CONVERTERS USED IN THE MITIGATION OF PARTIAL SHADING IN PV ARRAYS}

\section{A. Proposed System}

Interleaved converters have been proposed over 40 years ago as a prominent solution for general high-current applications [31]. This technique consists in the association of several converters in parallel, where each one of them is responsible for processing part of the total output power, thus reducing the current stress through semiconductor elements.

For high-current and voltage step-up applications, interleaving of several converters is very often employed to improve performance and reduce size, as shown in Figure 9. Besides, interleaving effectively doubles the switching frequency and also partially cancels the input and output ripples, as the size of the energy storage inductors and differential-mode electromagnetic interference (EMI) filter in interleaved implementations can be reduced [32].

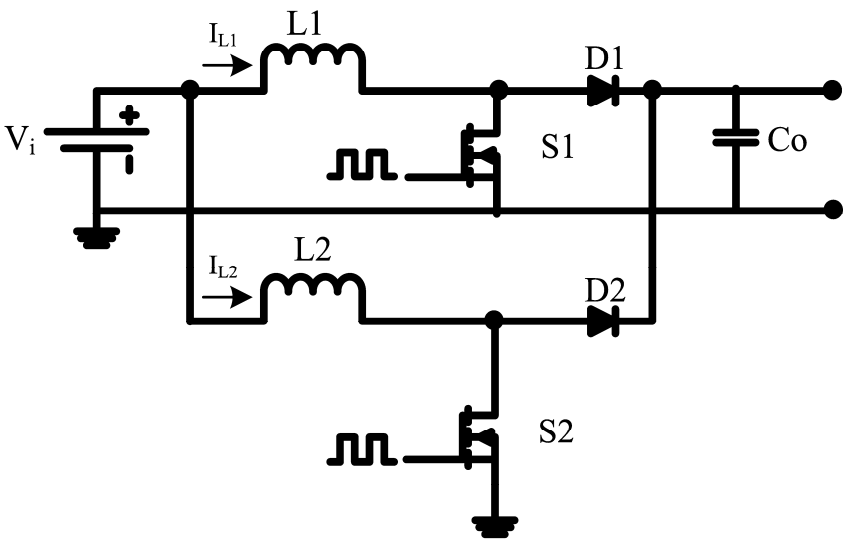

Fig. 9. Two-phase interleaved boost converter.

The interleaved boost converter, also known as multiphase dc-dc boost converter, is able to operate in either continuous conduction mode (CCM) or DCM, depending on the size of the filter inductor and also key parameters such as the switching frequency, input voltage, and load current.

In the interleaved boost converter shown in Figure 9, the drive signals of switches $S_{1}$ and $S_{2}$ must be phase-shifted by $2 \cdot \pi / m=2 \cdot \pi / 2=180^{\circ}$, where $m=2$ is the number of phases. In order to explain the operation in DCM, let us consider one of the phases composed by $L_{l}, S_{l}$, and $D_{l}$. In the first operating stage, switch $S_{I}$ is turned on, while diode $D_{I}$ is reverse biased and the output capacitor provides energy to the load. Besides, the current through $L_{l}$ increases linearly. In the second stage $S_{I}$ is turned off and $D_{l}$ is forward biased, as the energy stored in the inductor is delivered to the load and the output capacitor is charged. It is important to notice that the current through $L_{l}$ decreases linearly until it becomes null i.e. the inductor is fully discharged. This is the main difference between CCM and DCM. Finally, in the third stage, both $S_{I}$ and $D_{l}$ remain turned off and only the capacitor provides energy to the load.

The study developed in [33] and [34] shows that the converter efficiency is always higher for the converter operating in DCM, while reduced size of filter elements is also obtained. However, it is important to mention that in this mode the majority of DC-DC converters are accompanied with extremely high EMI levels. Generally, power converters manage the energy in a pulsating way but the use of interleaving technique provides a more continuous energy flow. From the point of view of conducted differential mode EMI, interleaved operation is very interesting, since the bad EMI behavior of switched converters is in part due to the fact that the energy is taken from the main source abruptly at high frequencies [35]. In the interleaved boost converter, CCM operation can be achieved even though each phase operates in DCM, as seen in Figure 10. That is, the size of boost inductors $L_{1}$ and $L_{2}$ can be reduced, while efficiency is significantly increased. Besides, the size of output capacitor $C_{o}$ is also reduced.

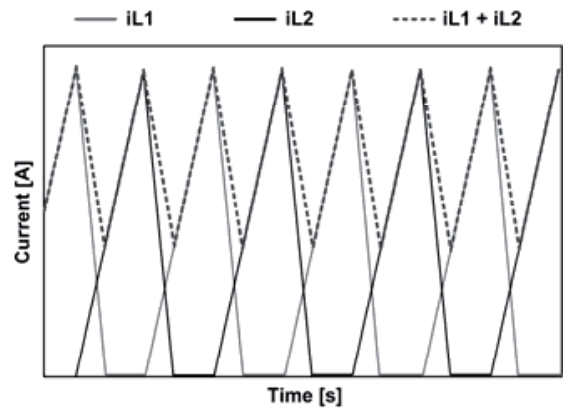

Fig. 10. Current through the boost inductors.

Considering the multi-input PV system shown in Figure 11 , the DCM interleaved boost converter can be used in an approach where the current or the voltage regarding each string can be controlled independently in such a way that the partial shading of a given cell or panel is not supposed to influence on the performance of the whole system.

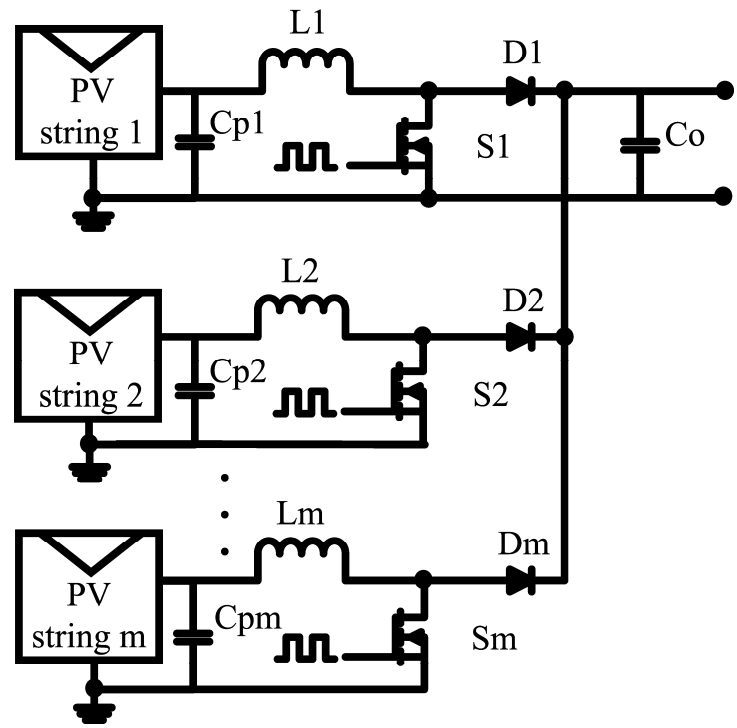

Fig. 11. Multi-input PV system based on the interleaved boost converter.

\section{B. Control System}

From the transfer function that represents the small signal model of the DCM boost converter, it is possible to properly design a controller so that the desired dynamic performance is achieved. By using small signal analysis, average current mode control can be implemented considering that the 
current through the boost inductor $i_{L}$ is the variable to be controlled, as shown in Figure 12, where $G_{c}(s)$ corresponds to the controller, $G_{P W M}(s)$ is the pulse width modulator, $G_{i d}(s)$ is the transfer function of the inductor current to the duty cycle, and $K_{i}$ is the current gain. Current $i_{L}$ is compared with a reference value $\left(i_{L}{ }^{*}\right)$, while the control signal can be adjusted and compared with a sawtooth wave, thus generating the proper duty cycle $(d)$. The control loop can then be implemented in each phase of the interleaved converter represented in Figure 11.

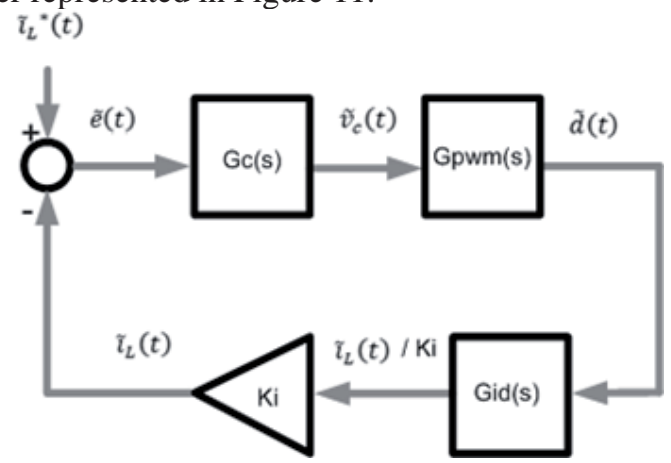

Fig. 12. Block diagram representing average current mode control.

The transfer function of the inductor current to the duty cycle can be determined by using either the average state space technique or the PWM switch model [36]. Both techniques are well known and its utilization will not be demonstrated here, while the following expression results:

$$
G_{i d}(s)=\left[\begin{array}{ll}
0 & 1
\end{array}\right] \cdot\left[\begin{array}{cc}
s-\frac{2 \cdot(1-U)}{D_{1} \cdot T_{s}} & \frac{2 \cdot U}{D_{1} \cdot R_{o} \cdot T_{s}} \\
-\frac{1}{C_{o}} & s+\frac{1}{R_{o} \cdot C_{o}}
\end{array}\right] \cdot\left[\begin{array}{c}
\frac{2 \cdot U \cdot V_{i}}{L} \\
-\frac{D_{1} \cdot T_{s} \cdot V_{i}}{L \cdot C_{o}}
\end{array}\right]
$$

where $D_{l}$ represents part of the switching period $T_{s}$ during which energy is stored in the boost inductor $L, R_{o}$ is the load resistance, $C_{o}$ is the output capacitor, $V_{i}$ is the input voltage, and $U$ is the static gain given by:

$$
U=\frac{V_{o}}{V_{i}}=\frac{1}{2}+\frac{1}{2} \cdot \sqrt{1+\frac{2 \cdot D_{1}^{2} \cdot R_{o} \cdot T_{s}}{L}}
$$

The procedure that allows the design of controller $G_{c}(s)$ using the $\mathrm{K}$ factor is well known in literature and detailed as follows [37]:

1. Plot the Bode diagram for the transfer function defined by (3) i.e. the transfer function of the current through the filter inductor to the control variable of the MPPT algorithm.

2. Choose the crossover frequency $f_{c}$, which must be less than one fourth of the switching frequency $f_{s}$.

3. Choose the phase margin.

4. Determine the gain of the compensator for which the closed-loop gain at the crossover frequency is unity.

5. Define angle $\alpha=\mathrm{M}-\mathrm{P}-90^{\circ}$, where $M$ is the desired phase margin and $P$ is the phase-shift angle of the system.

6. Choose the controller type. If $\alpha<90^{\circ}$, a PI controller is used. Otherwise, if $\alpha>90^{\circ}$, a PID controller is chosen.

7. Calculate the $\mathrm{K}$ factor.

8. Allocate poles and zeros for the controller according to the $\mathrm{K}$ factor.

\section{Implementation and Experimental Results}

Considering the representation in Figure 13, and also the conclusions obtained in Section II.C, an experimental prototype of the multi-input two-phase boost converter was implemented according to the specifications in Table III. IC using CMPPT was chosen in this case aiming to demonstrate that this method is as effective as $\mathrm{P} \& \mathrm{O}$. However, if a high number of PV strings is considered, high component count in terms of semiconductors and sensors with consequent increase of cost could be a disadvantage, especially if Hall current sensors are used.

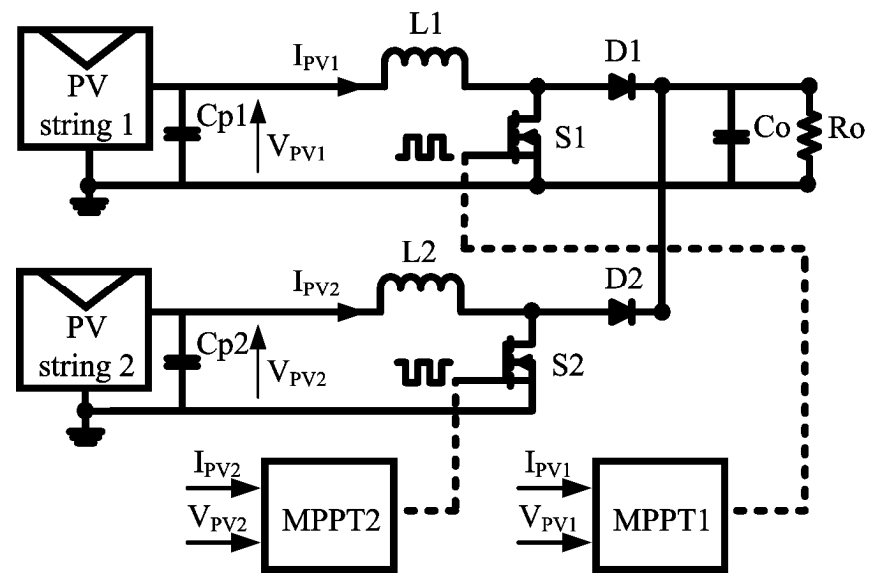

Fig. 13. Multi-input dc-dc interleaved boost converter operating in DCM used in MPPT.

TABLE III

Specifications of the experimental prototype.

\begin{tabular}{lc}
\hline \multicolumn{1}{c}{ Parameter } & Value \\
\hline Boost inductor & $L_{l}=L_{2}=170 \mu \mathrm{H}$ \\
\hline Input capacitor & $C_{p l}=C_{p 2}=100 \mu \mathrm{F}$ \\
\hline Output capacitor & $C_{o}=226 \mu \mathrm{F}$ \\
\hline Load resistance & $R_{o}=500 \Omega$ \\
\hline Switching frequency & $f_{s}=25 \mathrm{kHz}$ \\
\hline Sampling frequency of the inductor current & $f_{\text {samp }}=25 \mathrm{kHz}$ \\
\hline MPPT Algorithm & P\&O, CMPPT \\
\hline
\end{tabular}

The experimental setup is shown in Figure 14, where $A$ is the power converter, $B$ is the DSP board, $C$ is the drive circuitry, and $D$ is a digital oscilloscope. The converter uses two IGBT modules SK45GB063 and is controlled using DSP TMS320F2812 from Texas Instruments. Two strings using two series-connected BPSX120 modules are connected to each phase of the interleaved converter, whose total rated output power is $480 \mathrm{~W}$. The experimental tests using a pure resistive load were carried out with and without using the MPPT algorithm and are discussed as follows.

The currents through the boost inductors are represented in Figure 15, where it can be seen that the converters operate in DCM. Besides, perfect current sharing is not maintained because the irradiance levels for the PV strings are not the same.

The behavior of the current through one of the inductors and also the PV string current when MPPT is not implemented is shown in Figure 16. A positive step of 200 
$\mathrm{mA}$ is applied to the reference current, demonstrating that the controller response is fast when such disturbance occurs.

The current and voltage waveforms for each one of the strings are depicted in Figure 17. The MPPT algorithm was only implemented in one of the converters $(\mathrm{CH} 1$ and $\mathrm{CH} 2)$, while the extracted power corresponds to about $84 \mathrm{~W}$. The remaining one was driven with fixed duty cycle $(\mathrm{CH} 3$ and $\mathrm{CH} 4$ ), and the extracted power in this case is only $39 \mathrm{~W}$.

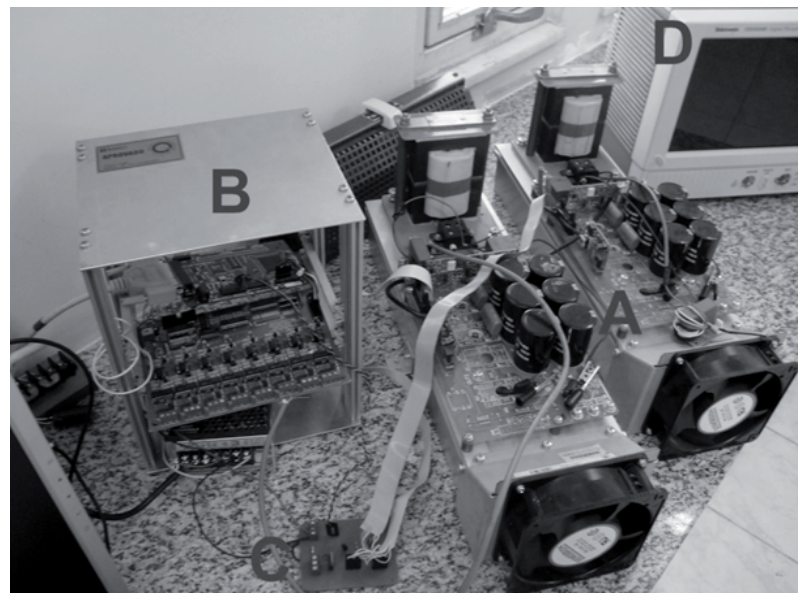

Fig. 14. Experimental prototype.

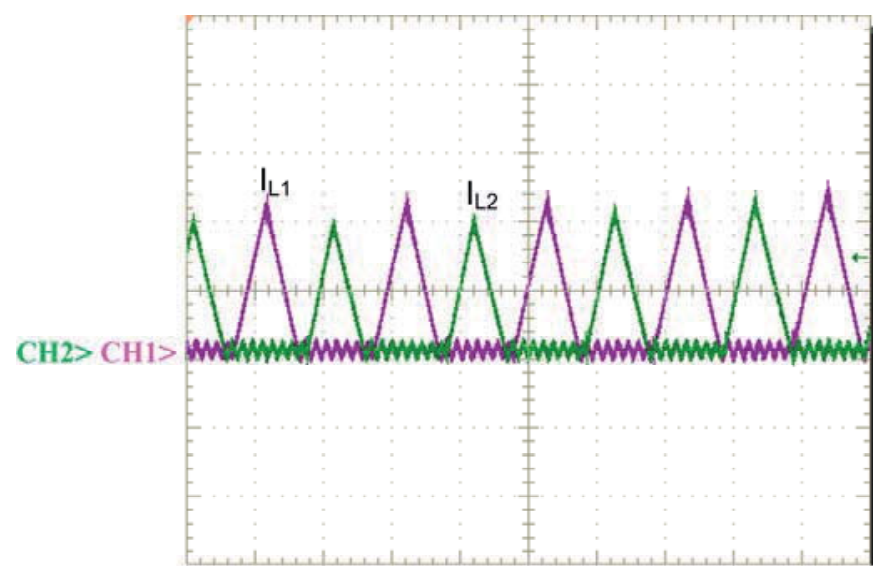

Fig. 15. Currents through boost inductor $L_{1}\left(I_{L I}-\mathrm{CH} 1-500\right.$ $\mathrm{mA} /$ div., $20 \mu \mathrm{s} / \mathrm{div}$.) and $L_{2}\left(I_{L 2}-\mathrm{CH} 2-500 \mathrm{~mA} / \mathrm{div} ., 20 \mu \mathrm{s} / \mathrm{div}.\right)$.

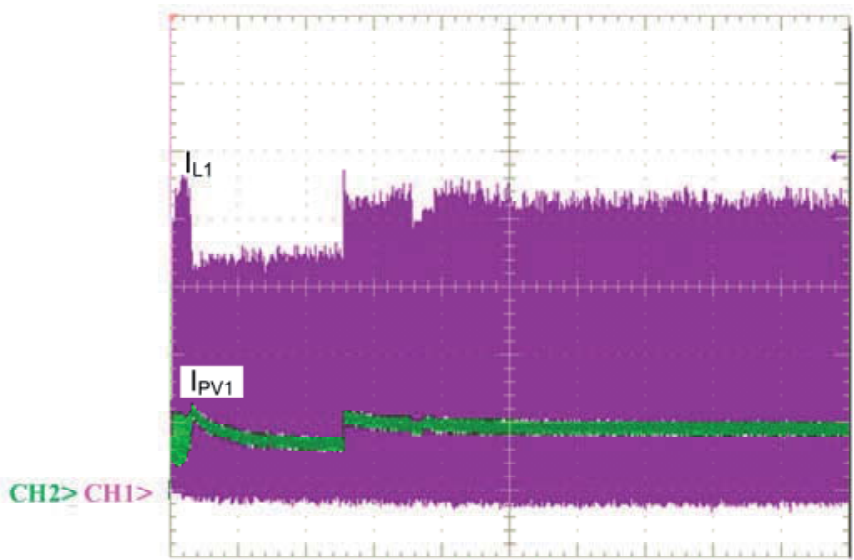

Fig. 16. Current through boost inductor $L_{I}\left(I_{L I}-\mathrm{CH} 1-500\right.$ $\mathrm{mA} /$ div., $200 \mathrm{~ms} /$ div. $)$ and PV string 1 current $\left(I_{P V l}-\mathrm{CH} 2-500\right.$ mA/div., $200 \mathrm{~ms} /$ div.).
MPPT is now implemented for both strings and the waveforms shown in Figure 18 were acquired. Compared to the results obtained in Figure 17, it can be seen that PV string 2 is now able to extract $105 \mathrm{~W}(\mathrm{CH} 3$ and $\mathrm{CH} 4)$ from the sun, that is, the extracted power has increased significantly. It is also worth to mention that both current and voltage waveforms do not remain constant due to eventual changes in the solar irradiance. This result is particularly important because it demonstrates that it is possible to control both phases of the interleaved converter in a simultaneous and individual form, also enabling MPPT. Besides, the currents in Figure 18 show that the strings are subjected to distinct irradiance and/or temperature levels.

Finally, Figure 19 shows the behavior of the PV system when one of the strings is intentionally covered with black plastic, thus emulating the effect of partial shading. It can be clearly seen that power extraction of the remaining string is not affected, while maximum power is obtained.

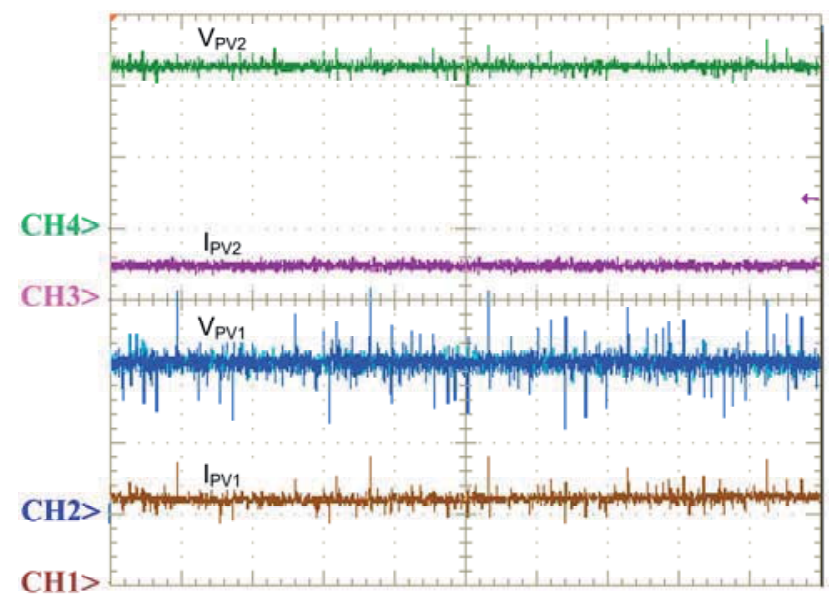

Fig. 17. PV string 1 current $\left(I_{P V l}-\mathrm{CH} 1-1 \mathrm{~A} /\right.$ div., 2 s/div. $)$ and voltage $\left(V_{P V I}-\mathrm{CH} 2-35 \mathrm{~V} /\right.$ div., $2 \mathrm{~s} /$ div.), and PV string 2 current $\left(I_{P V 2}-\mathrm{CH} 3-1 \mathrm{~A} /\right.$ div., 2 s/div. $)$ and voltage $\left(V_{P V 2}-\mathrm{CH} 4-35\right.$ V/div., 2 s/div.).

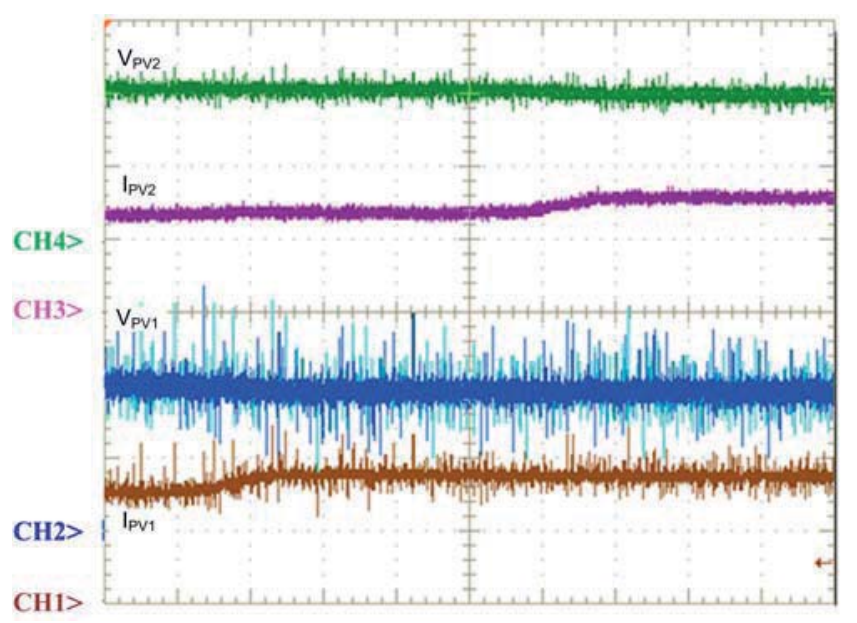

Fig. 18. PV string 1 current $\left(I_{P V 1}-\mathrm{CH} 1-1 \mathrm{~A} /\right.$ div., $40 \mathrm{~s} /$ div. $)$ and voltage ( $V_{P V I}-\mathrm{CH} 2-35 \mathrm{~V} /$ div., $40 \mathrm{~s} /$ div.), and PV string 2 current $\left(I_{P V 2}-\mathrm{CH} 3-1 \mathrm{~A} /\right.$ div., $40 \mathrm{~s} /$ div. $)$ and voltage $\left(V_{P V 2}-\mathrm{CH} 4-35\right.$ V/div., 40 s/div.). 


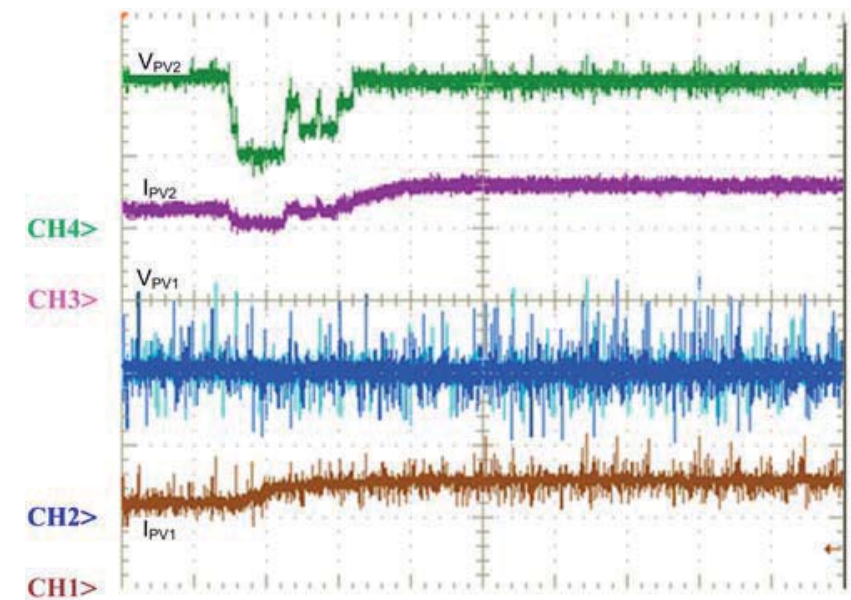

Fig. 19. PV string 1 current $\left(I_{P V l}-\mathrm{CH} 1-1 \mathrm{~A} /\right.$ div., $10 \mathrm{~s} /$ div. $)$ and voltage $\left(V_{P V I}-\mathrm{CH} 2-35 \mathrm{~V} /\right.$ div., $10 \mathrm{~s} /$ div. $)$, and PV string 2 current $\left(I_{P V 2}-\mathrm{CH} 3-1 \mathrm{~A} /\right.$ div., $10 \mathrm{~s} /$ div. $)$ and voltage $\left(V_{P V 2}-\mathrm{CH} 4-35\right.$ V/div., 10 s/div.).

\section{CONCLUSION}

This paper has presented the study and implementation of a multi-input interleaved boost converter operating in DCM with the aim of achieving high efficiency and possible modular expansion in a PV energy system.

The first part of the paper has investigated the performance of popular MPPT techniques such as $\mathrm{P} \& \mathrm{O}$ and IC, which are simpler approaches if compared to other solutions. Since there are no conclusive results in literature on the control of current or voltage of a PV string to achieve MPPT, some simulation results regarding VMPPT and CMPPT have shown that the obtained results are nearly the same regarding performance and efficiency. However, current control may present some drawbacks if the disturbance step of the algorithm is not appropriately chosen e.g. is too large. However, CMPPT becomes more interesting when the design of the control system regarding the static power converter is considered.

The ratio between the current at maximum power the short-circuit current is generally higher than that between the voltage at maximum power and the open circuit voltage. Thus, relatively large disturbance steps can lead to saturation of the panel current to the short-circuit condition, with consequent loss of efficiency in MPPT. This is less likely to happen with voltage control. However, as shown by the simulation results, one can properly choose the disturbance step and the sampling frequency to avoid such problems, making it virtually irrelevant to choose either voltage or current of the PV panel to track the MPP.

The second part of the paper is focused on mitigating the undesirable effects of partial shading in the power extraction of a PV array by using a multi-input approach based on the DCM interleaved boost converter. Of course, the use of interleaved converters to achieve individual MPPT in several strings is not novel, according to [15]. However, the association of one string per phase of a DCM interleaved boost converter had not yet been considered as a possible solution in this case.
The proposal of this work is particularly interesting even when a greater number of strings is arranged in the roof of a residence, where different angles of inclination typically exist. The minimized volume and weight associated with multiple inputs may be attractive if other similar approaches are considered.

Experimental results have shown that MPP for each string can be tracked individually, while the performance of a given string is not supposed to influence on the remaining ones. The performance of the IC algorithm has proven to be satisfactory, mainly because significant increase in the extracted power exists when it is employed in the PV system. Besides, the effect of partial shading has been mitigated since MPP is individually tracked for each phase of the dc-dc converter.

\section{ACKNOWLEDGMENT}

The authors gratefully acknowledge CNPq, CAPES, FAPEMIG, and INERGE for the support to this work.

\section{REFERENCES}

[1] B. L. A. Silva, J. M. S. Lafay, and F. L. Tofoli, "Case Study: Hydroelectric Generation Employing The Water Distribution Network in Pato Branco, Brazil", Proc. Tenth IASTED European Conference on Power and Energy Systems (EUROPES 2011), 2011. pp. 50-54.

[2] J. T. Bialasiewicz, "Renewable Energy Systems with Photovoltaic Power Generators: Operation and Modeling," IEEE Transactions on Industrial Electronics, vol. 55, no. 7, pp. 2752-2758, July 2008.

[3] P. G. Barbosa, H. A. C. Braga, M. C. B. Rodrigues, and E. C. Teixeira, "Boost Current Multilevel Inverter and Its Application on Single-Phase Grid-Connected Photovoltaic Systems," IEEE Transactions on Power Electronics, vol. 21, no. 4, pp. 1116-1124, July 2006.

[4] W. Xiao, M. G. J. Lind, W. G. Dunford, and A. Capel, "Real-Time Identification of Optimal Operating Points in Photovoltaic Power Systems," IEEE Transactions on Industrial Electronics, vol. 53, no. 4, pp. 1017-1026, Aug. 2006.

[5] M. Veerachary, T. Senjyu, and K. Uezato, "Maximum Power Point Tracking of Coupled Inductor Interleaved Boost Converter Supplied PV System," IEE Proceedings - Electric Power Applications, vol. 150, no. 1, pp. 71-80, Jan. 2003.

[6] M. A. G. Brito, L. P. Sampaio, L. G. Junior, and C. A. Canesin, "Contribuição ao Estudo dos Principais Algoritmos de Extração da Máxima Potência dos Painéis Fotovoltaicos," Revista Eletrônica de Potência, Campo Grande-MS, pp. 592-600, vol. 17, no. 3, Jun./Ago. 2013. (in Portuguese).

[7] Y. Huang, M. Shen, and F. Z. Peng, "A Z-source Inverter for Residential Photovoltaic Systems," IEEE Transactions on Power Electronics, vol. 21, no. 6, pp. 1776-782, Nov. 2006.

[8] T. Esram and P. L. Chapman, "Comparison of Photovoltaic Array Maximum Power Point Tracking Techniques," IEEE Transactions on Energy Conversion, vol. 22, no. 2, pp. 439-449, June 2007. 
[9] S. Jain and V. Agarwal, "Comparison of The Performance of Maximum Power Point Tracking Schemes Applied to Single-stage Grid-Connected Photovoltaic Systems," IET Electric Power Applications, vol. 1, no. 5, pp. 753-762, 2007.

[10] R. Faranda, S. Leva, and V. Maugeri, "MPPT Techniques for PV Systems: Energetic and Cost Comparison," in Proc. IEEE Power and Energy Society General Meeting - Conversion and Delivery of Electrical Energy in the 21st Century, 2008, pp. 1-6.

[11] B. I. Rani, G. S. Ilango, and C.Nagamani, "Enhanced Power Generation From PV Array Under Partial Shading Conditions by Shade Dispersion Using Su Do Ku Configuration," IEEE Transactions on Sustainable Energy, vol. 4, no. 3, pp. 594-601, Mar. 2013.

[12] E. Koutroulis and F. Blaabjerg, "A New Technique for Tracking the Global Maximum Power Point of PV Arrays Operating Under Partial-Shading Conditions," IEEE Journal of Photovoltaics, vol. 2, no. 2, pp. 84-90, 2012.

[13] E. Karatepe, Syafaruddin, and T. Hiyama, "Simple and High-Efficiency Photovoltaic System Under NonUniform Conditions," IET Renewable Power Generation, vol. 4, no. 4, pp. 354-368, 2010.

[14] L. Gao, R. A. Dougal, S. Liu, and A. Iotova, "ParallelConnected Solar PV System to Address Partial and Rapidly Fluctuating Shadow Conditions," IEEE Transactions on Industrial Electronics, vol. 56, no. 5, pp. 1548-1556, May 2009.

[15] S. Poshtkouhi and O. Trescases, "Multi-Input SingleInductor DC-DC Converter for MPPT in ParallelConnected Photovoltaic Applications," in Proc. 26th Annu. IEEE Applied Power Electronics Conf. Expo., 2011, pp. 41-47.

[16] S. Vighetti, J.-P. Ferrieux, and Y. Lembeye, "Optimization and Design of A Cascaded DC/DC Converter Devoted to Grid-Connected Photovoltaic Systems," IEEE Transactions on Power Electronics, vol. 27, no. 4, pp. 2018-2027, Apr. 2012.

[17] N. Femia, M. Fortunato, G. Lisi, G. Petrone, G. Spagnuolo, and M. Vitelli, "Guidelines for The Optimization of The P\&O Technique in GridConnected Double-Stage Photovoltaic Systems," in Proc. IEEE International Symposium on Industrial Electronics, 2007, pp. 2420-2425.

[18] N. Femia, G. Petrone, G. Spagnuolo, and M. Vitelli, "Optimizing Duty-Cycle Perturbation of P\&O MPPT Technique," in Proc. IEEE 35th Power Electronics Specialists Conference, 2004, vol. 3, pp. 1939-1944.

[19] N. Femia, G. Petrone, G. Spagnuolo, and M. Vitelli, "Optimizing Sampling Rate of P\&O MPPT Technique," in Proc. IEEE 35th Annual Power Electronics Specialists Conference, 2004, vol. 3, pp. 1945-1949.

[20] N. Femia, G. Petrone, G. Spagnuolo, and M. Vitelli, "Optimization of Perturb and Observe Maximum Power Point Tracking Method," IEEE Transactions on Power Electronics, vol. 20, no. 4, pp. 963-973, Jul. 2005.

[21] K. H. Hussein, I. Muta, T. Hoshino, and M. Osakada, "Maximum Photovoltaic Power Tracking: An
Algorithm for Rapidly Changing Atmospheric Conditions," IEE Proceedings - Generation, Transmission and Distribution, vol. 142, no. 1, pp. 5964, 1995.

[22] R. L. Carletti, L. C. G. Lopes, and P. G. Barbosa, "Active and Reactive Power Control Scheme for A Grid-Connected Photovoltaic Generation System Based on VSI with Selective Harmonic Elimination," in Proc. 8th Brazilian Power Electronics Conference, 2005, pp. $1-8$.

[23] M. G. Villalva, J. R. Gazoli, and E. Ruppert, "Analysis and Simulation of The P\&O MPPT Algorithm Using A Linearized PV Array Model," in Proc. 35th Annual Conference of IEEE Industrial Electronics, 2009, pp. 231-236.

[24] M. G. Villalva, T. G. de Siqueira, and E. Ruppert, "Voltage Regulation of Photovoltaic Arrays: SmallSignal Analysis and Control Design," IET Power Electronics, vol. 3, no. 6, pp. 869-880, 2010.

[25] W. Xiao, P. R. Palmer, and A. Capel, "Regulation of Photovoltaic Voltage," IEEE Transactions on Industrial Electronics, vol. 54, no. 3, pp. 1365-1374, Jun. 2007.

[26] W. Xiao and W. G. Dunford, "Topology Study of Photovoltaic Interface for Maximum Power Point Tracking", IEEE Transactions on Industrial Electronics, vol. 54, no. 3, pp. 1696-1704, Jun. 2007.

[27] S. Lee, J-E. Kim, and H. Cha, "Design and Implementation of Photovoltaic Power Conditioning", Journal of Electrical Engineering \& Technology, vol. 5, no. 4, pp. 606-613, 2010.

[28] M. A. S. Masoum, H. Dehbonei, and E. F. Fuchs, "Theoretical and Experimental Analysis of Photovoltaic Systems with Voltage and Current-Based Maximum Power Point Tracking", IEEE Transactions on Energy Conversion, vol. 17, no. 4, pp. 514-522, Dec. 2002.

[29] BP SX 120 - 120-Watt Multicrystalline Photovoltaic Module. Available at http://www.solarcellsales.com/ techinfo/docs/BP_SX_120_Data_Sheet.pdf. Acessed on May 20th, 2013.

[30] E. Galvani and I. de A. Souza, "Representação Gráfica dos Elementos do Clima: Estudo Comparativo entre Maringá, PR e Botucatu, SP”, GEOUSP - Espaço e Tempo, São Paulo, no. 19, pp. 131-140, 2006 - in portuguese.

[31] D. R. Garth, W. J. Muldoon, G. C. Benson, and E. N. Costague, "Multi-phase, $2 \mathrm{~kW}$, High Voltage, Regulated Power Supply", in Proc. IEEE Power Conditioning Specialists Conf., p.110, 1971.

[32] C. A. Gallo, F. L. Tofoli, and J. A. C. Pinto, "A Passive Lossless Snubber Applied to the AC-DC Interleaved Boost Converter," Transactions on Power Electronics, vol. 25, no. 3, pp. 775-785, Mar. 2010.

[33] G. Palumbo and W. Aloisi, "Efficiency Model of Boost DC-DC PWM Converters," International Journal of Circuit Theory and Applications, vol. 33, no. 5, pp. 419-432, May 2005.

[34] S. Ebaili and B. Betka, "Efficiency Model of DC/DC PWM Converter Photovoltaic Applications," in Proc. Global Conference on Renewables and Energy Efficiency for Desert Regions, 2009. 
[35] P. Zumel, O. Garcia, J. A. Oliver, and J. A. Cobos, "Differential-Mode EMI Reduction in A Multiphase DCM Flyback Converter," IEEE Transactions on Power Electronics, vol. 24, no. 8, pp. 2013-2020, Aug. 2009.

[36] V. Vorpérian, "Simplified Analysis of PWM Converters Using Model of PWM Switch. Part II: Discontinuous Conduction Mode," IEEE Transactions on Aerospace and Electronic Systems, vol. 26, no. 3, pp. 497-505, May 1990.

[37] H. D. Venable, "The K-Factor: A New Mathematical Tool for Stability Analysis and Synthesis," in Proc. Powercon, 1983, San Diego, USA.

\section{BIOGRAPHIES}

Pedro de Assis Sobreira Jr. received the B.Sc. and M.Sc. degrees in electrical engineering from the Federal University of Juiz de Fora, Juiz de Fora, Brazil, in 2009 and 2011, respectively.

His research interests include power electronic converter topologies, digital control, and renewable energy sources.

Fernando Lessa Tofoli received the B.Sc., M.Sc., and $\mathrm{Ph} . \mathrm{D}$. degrees in electrical engineering from the Federal University of Uberlândia, Uberlândia, Brazil, in 1999, 2002, and 2005, respectively.

Currently, he is a Professor with the Federal University of São João del-Rei, São João del-Rei, Brazil. His research interests include power-quality-related issues, high-power factor rectifiers, and soft switching techniques applied to static power converters.

Henrique Antônio Carvalho Braga received the B.Sc. degree in electrical engineering from the Federal University of Juiz de Fora, Juiz de Fora, Brazil, in 1982, the M.Sc. degree in electrical engineering from the Federal University of Rio de Janeiro, Rio de Janeiro, Brazil, in 1988, and the Ph.D. degree in electrical engineering from the Federal University of Santa Catarina, Florianopólis, Brazil in 1996.

Currently, he is a Professor with the Federal University of Juiz de Fora, Juiz de Fora, Brazil. His research interests are mainly related to the power electronics field, including multilevel converters, Spice modeling of power electronics circuits and devices, active power filters, high power factor rectifiers, photovoltaic conversion systems, and energyefficient lighting.

Pedro Gomes Barbosa received the B.S. degree in electrical engineering from the Federal University of Juiz de Fora, Juiz de Fora, Brazil, in 1986, and the M.Sc. and the D.Sc. degrees in electrical engineering form the Federal University of Rio de Janeiro, Rio de Janeiro, Brazil, in 1994 and 2000, respectively.

Currently, he is a Professor with the Federal University of Juiz de Fora, Juiz de Fora, Brazil. His main research interests are multilevel and multipulse converters, renewable energy sources, active power filters, and static power compensators for FACTS applications.

André Augusto Ferreira received the electrical engineering degree from the Federal University of Juiz de Fora, Juiz de Fora, Brazil, in 2000, and the M.Sc. and the $\mathrm{Ph} . \mathrm{D}$. degrees in electrical engineering from State University of Campinas in 2002 and 2007, respectively.

Currently, he is a Professor with the Federal University of Juiz de Fora, Juiz de Fora, Brazil. His research interest includes dc-dc power converters control, digital control, power quality, and fuel cell and ultracapacitor applications. 